\title{
Ruben A.
}

\section{0 dramaturgo do travestimento da forma}

\section{Mickael de Oliveira}

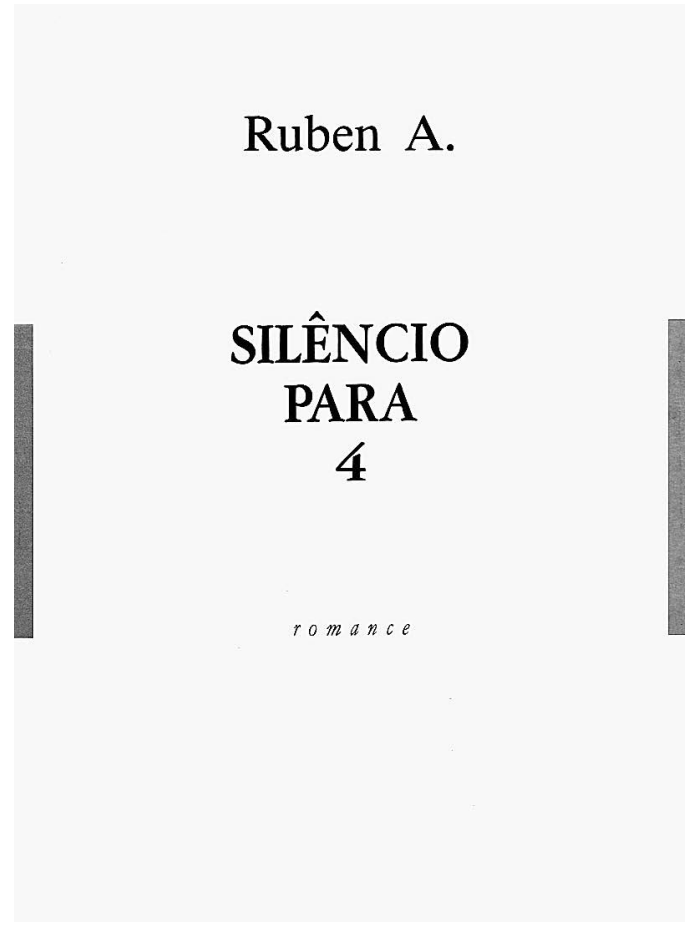

1.

Formado entre Coimbra e Lisboa em Ciências Históricofilosóficas, tendo sido depois diplomata, professor e investigador, o escritor português, Ruben Andresen Leitão, Ruben A., (1920-1975), que se definia como "meio nórdico meio lisboeta" (A. 2001: 59-60), conseguiu alcançar duas metas na maior parte dos seus textos que o tornam ainda hoje um autor invulgar: por um lado, atinge um leque de estilos formais tão diverso que, aberto, nos devolve uma lógica de construção totalmente fragmentada (numa mesma obra identificamos o uso de vários géneros, como a epistola, a narrativa, a diarística, e até o drama); por outro lado, torna toda a sua bibliografia na sua própria biografia ${ }^{1}$. Porém, o que nos leva até estas páginas não são os géneros mais conhecidos e usados por Ruben $A$. mas um outro que também funcionou como uma realidade espelhada, o drama, tendo legado aos estudiosos um corpus dramático fundamental e importante para reavaliar a dramaturgia portuguesa da década de 60 e 70.

Embora com actividades esparsas, a sua profissão de peso foi a de escriba dos assuntos do quotidiano e escritor, ou melhor, redactor do seu tempo, missão que acabou com a interrupção da obra Kaos, ao falecer vítima de um enfarte de miocárdio em 1975, depois de ter recebido um
Ruben A., Silêncio para 4 (1. a ed. 1973), Lisboa, Assírio \&t Alvim, 1990, 206 pp.

convite para leccionar como professor associado na Universidade de Oxford. Tencionava depois de Kaos, dedicar-se totalmente ao teatro, após ter escrito algumas peças e visto muitas outras entre Lisboa e Londres. 0 seu corpus dramático assenta convencionalmente sobre quatro textos: os dramatículos Triálogo (1951) e 0 fim de Orestes (1963); os dramas mais extensos e significantes, Júlia (1963) e Relato 1453 (1965). Este quarteto poderia ser completado, fora da convenção, com o texto que ele próprio quis chamar de "romance": Silêncio para 4 e que será o objecto deste estudo, num esforço crítico que pretende contribuir para reabilitar e legitimar a entrada de Silêncio no corpus dramático do autor.

À primeira vista, um dos motivos que nos leva à conclusão de que Silêncio para 4 se inclui neste corpus baseia-se no facto de todo o tecido linguístico ser composto exclusivamente por diálogos. É um diálogo assustadoramente cénico, líquido, ritmico, que confessa tacitamente a ironia de Ruben A., ao carimbar o texto como género romanesco. Portanto, o prelúdio argumentativo que se segue é simples, mas, antes de começarmos a análise de Silêncio, falemos do teatro de Ruben $A$. e das referências inglesas que se materializaram em Júlia.

"Dia seguinte. A vida em Portugal raras vezes acontece. Temos de ir à procura dela, quando não morremos de tédio. Uma pessoa tem de tomar o comboio, um automóvel, uma laranjada ou um avião para ir ter com a vida."

(A.,Ruben. 2000: 66)

2.

As referências teatrais estão por toda a parte na sua obra autobiográfica, o que o demonstra, antes de mais, como um observador atento aos palcos de Lisboa e Londres, aquando das suas estadias como estudante e professor. Os seus gostos poderão ser um caminho para entender a poética teatral em causa. Nas Páginas $V$, escreve:

"Antevéspera - Relative Values, de Noel Coward. Um bom bocado de noite - o teatro casual inglês é imbatível (...) esmaga-me pensar no teatro inglês. Tenho umas saudades de Shakespeare, Eliot, Shaw, Christopher Fry e dos actores" (A. 2001: 65). Aliás, para Ruben A., a referência do teatro de língua inglesa é primordial, e é ali que vai procurar a verve que caracteriza algumas das suas peças. $E_{\text {, facto }}$ não menos interessante, colocará mesmo esta dramaturgia londrina acima dos autores que fizeram o teatro parisiense
1 Sobretudo 0 mundod minha procura I, II, III e Páginas I-VI.

Mickael de Oliveira é investigador em Estudos Teatrai (doutorando pela Faculdade de Letras da Universidade de Lisboa) e bolseiro da FCT, trabalhando na área da dramaturgia contemporânea portuguesa e europeia. É também autor de vários textos para palco, e exerce a sua escrita como dramaturgo/ dramaturgista no Colectivo 84. 
da década de 50, seus contemporâneos, criticando com ironia, em Páginas VI, os principais mentores do teatro do absurdo. No fragmento dedicado ao encontro pessoal com T. S. Eliot, afirma o seguinte: "Dormitámos um pouco, eu sempre de olho vivo à espera de absorver mais uma pitada quando pensava que ainda não tinha passado seis meses que assistira, em Londres, à representação da sua peça A reunião de família. E bem impressionado ficara?! Só eu sei. Caramba, aquilo era teatro de novo calibre, tornava o resto obsoleto. Depois apareceram os lonescos, os Becketts, eles estão nas entrelinhas de Eliot."

Mais uma vez em sentido contrário (à moda de Caranguejo), pois aquele que se tinha aproximado do surrealismo na narrativa (romance e conto), ao qual mantinha ainda uma relação de vaivém, negava o Teatro do Absurdo. Esta atitude é paradoxal, pois as linhas entre o Teatro Surrealista e o Teatro do Absurdo são apesar de tudo ténues. Em Portugal, prefere-se falar muitas vezes em teatro surrealizante ou próximo do surrealismo, para tenta abarcar os textos próximos de uma estética bretoniana. Luiz Francisco Rebello mescla mesmo as duas correntes, asseverando que a "matriz surrealista do teatro do absurdo está patente nos primeiros exercícios teatrais de Natália Correia: Sucumbina ou a teoria do Chapéu (1952), escrito em colaboração com Manuel Lima (...) e da estética surrealista ficaram ainda vestígios num drama de alta voltagem poética e paroxistica violência, $A$ Pécora, escrito em 1966 e inédito até 1983 em que, como justamente observou o crítico Carlos Porto, 'se consegue o aparentemente impossivel: conciliar Genet e Brecht."

"Em Portugal Camões liquidou tudo porque cada vez que, no nosso pais, se escrevia qualquer coisa vinha logo o pateta do senso comum a dizer. Mas meu caro, isso depois de Camões é pifio e não tem belez pátria nem queridas linhas. Assim, à sombra duma bananeira inquisitorial impediram-se o aparecimento normal dos poetas e dramaturgos (...)" (A., Ruben 2000: 183)

3.

0 seu fascinio pelo teatro inglês, tendo como pilares referenciais Shakespeare e T.S. Eliot, contrasta com a crítica que faz ao teatro português, motivada nomeadamente

'Luiz Francisco Rebello Breve história do teatro português, Lisboa, Publicações EuropaAmérica, 2000, p. 153

José Carlos Seabra Pereira, "Ruben A.: Para animar o real", in 0 mundo à minha procura: Ruben A. trinta anos depois, Coimbra, Imprensa da Universidade de Coimbra, 2006, p. 24. pela falta de clareza na crítica social (sendo a bruma essencia para passar a censura), no uso de um teatro alegórico, quer através do teatro do onírico absurdo-surrealizante (Natália Correia, H. Prista Monteiro, J. Salazar Sampaio, Pedro Barbosa), quer através do uso de um teatro épicoreal-socialista (Alves Redol, B. Santareno, Romeu Correia) Ora, tanto Júlia como Silêncio para 4 não poderão ser incluidos (facilmente) em qualquer uma destas categorias. Por motivos de ordem prática, não poderei neste artigo prolongar-me mais sobre a peça ímpar que é Júlia permanecendo ainda um enigma para os palcos portugueses. E é com Júlia que o teatro português conhece (talvez) um dos textos com trechos mais fortemente realistas da sua década, não hesitando em dar nomes às coisas, tornando-

as concretas, nomeando as cidades, a época, os dias, as ruas, as estradas, as pessoas, tanto as comuns como as que fizeram história, indo ao pormenor de convocar nomes de empresas como a Nestlé. Ruben A. não teme desvirtuar a arte pregando-a ao solo. Podíamos ver nesta tentativa de fixar o texto num meio ambiente específico como uma das primeiras experiências como um certo hiper-realismo que Jorge Silva Melo cumprirá plenamente na década de 90, com António, um rapaz de Lisboa.

Debrucemo-nos agora sobre Silêncio para 4, escrito em 1973. 0 texto é, no mínimo, uma obra sui generis que ultrapassa, tal como toda a sua obra, a imposição das categorias, até mesmo a distinção entre os géneros literários. 0 que é Um adeus aos deuses? 0 que são as Páginas? Um conjunto de textos com cheiro a diário, a epistola, a artigo de opinião, a prosa poética. José Carlos Seabra Pereira escreve que "é essa luz que se deve valorizar, a diluição das demarcações genológicas (...) Ruben A. preferia ver considerada [a sua obra] como romance de indagação subjectiva ("toda a minha obra", dizia ele no Diário de Lisboa em 13.01.1966, "é um romance, uno, indestrutivel, absoluto, por vezes traz a etiqueta de conto teatro, diário, viagem, auto-biografia, novela, mas no fundo é todo de um romance."

Estando os géneros diluídos, numa refundição "transgenológica" ou de "transgénero", é de todo pertinente asseverar que Silêncio para 4 pertence a esse universo literário transversal, mas que, mesmo assim, comparando entre os géneros, a configuração de Silêncio avizinha-se mais de um drama do que de um romance. Assim, poderíamos, quando muito, considerar Silêncio Para 4 uma obra que opera entre os géneros, característica pósmoderna da arte e da literatura contemporâneas

0 que o autor faz é inscrever na capa do livro um sistema semântico antitético. Se, por um lado, não encontramos nenhum "silêncio para quatro" ao lermos o livro, encontrando sim um fluxo de palavras rompendo as leis da gramática e da pontuação para manter a energia e velocidade, por outro, também não identificamos nunca os elementos constitutivos do romance tradicional. Assim, tal como não há silêncio, também não há romance, reflectindo mais uma vez o humor inteligente e irónico que Ruben A. sempre cultivou, tanto no teatro como na prosa, deturpando o sentido primário das coisas, apanágio dos dadaístas e surrealistas. Para que o texto passasse sem polémica a incorporar o corpus dramático da sua obra bastaria que, com uma caneta, se colocasse por detrás dos travessões das falas o nome tautológico das personagens Ele e Ela. E, contudo, não encontramos nunca uma palavra que fuja à regra teatral do diálogo, não havendo sequer a existência de um narrador, de um Eu ou de um Deus que conduza a fábula. Tudo é diálogo, tudo é jogo dramático encenado, até nas didascálias que assinalam o movimento das personagens, subtilmente incrustadas nas próprias falas, à boa maneira do teatro clássico. 
Em Páginas V, escreve acerca do seu "drama": "Dia 5. Do Caranguejo quase nada. Uma carta de Jorge de Sena e a critica de Urbano Tavares Rodrigues (...) Apetece-me escrever um livro só dialogado. Pegar em meia dúzia de personagens, pessoas reais, e pô-las a falar normal no seu dizer de baboseiras - que afinal é aquilo que nos comanda e que dizemos nós todos uns aos outros" (A. 2000: 115). A coloquialidade torna-se a matéria-prima nos seus principais dramas, em Júlia e em Silêncio para 4, ingrediente já mesclado noutras obras prosaicas. Tal como a linguagem, o tema principal tratado pretende-se trivial, procurando seguir as palavras que redigiu em Páginas V: "Oual a realidade pergunto eu? Shakespeare responde-me imediatamente - é corriqueira, eis outra grandeza alheia a Wagner" (A. 2000: 205).

Se o tema é corriqueiro em Silêncio, já a realidade e linguagem não o são, bem como todo o tratamento poéticorealista que se oferece ao tema principal, o qual se poderia intitular "conversação entre dois ou quatro amantes". Os vários tópicos temáticos estão quase todos mergulhados num banho erótico invulgar para a época e para a dramaturgia portuguesa de então, centrada nas problemáticas sócio-políticas, ainda que na maior parte alegóricas, provocadas pelo Estado Novo (ressalvando, porém, os textos de Santareno que expõem de uma forma corajosa os tabus e tensões sexuais nas comunidades humanas mais fechadas, como sucede em A Promessa e 0 pecado de João Agonia).

Eduardo Lourenço, no prefácio escrito para a publicação do livro, diz lapidarmente que "Nunca em língua portuguesa se ilustrou com tão jubilante desvairo a palavra conhecida de Nietzsche: o amor é o ódio mortal dos sexos" ${ }^{\prime \prime}$. Na verdade, Silêncio para 4 manifesta-se como ária ao corpo, ao erotismo, à satisfação do desejo antinómico: as complicações da mente, perplexidades morais e sentimentais. A sua maneira "sem rodeios" de falar sobre sexo aproxima ainda o autor português de uma linguagem libidinosa de cariz moderno, inaugurada décadas antes por Henry Miller, a que Eduardo Lourenço faz referência. Mesmo assim, como autor português, conserva um certo pudor lusitano, permanecendo longe da crueza milleriana de Trópico de Câncer: "Fodo-te, Tânia, para que permaneças fodida. (...) Arrancar-te-ei alguns cabelos da cona e colocá-los-ei no queixo do Bóris. Cravarei os dentes no teu clitoris e cuspirei duas moedas de franco." ${ }^{5}$

Ruben A. afasta-se, portanto, dessa brutalidade literal, rondando todavia esse universo, nalgumas falas femininas: "Não percebes que sou mulher, que falo pelo útero? Não percebes?! Não percebes que ter-te dentro de mim é que é possuir-te! Quero protecção, quero-te espalmado em cima de mim, quero-te acocorado, ressono corpulento nos princípios do suor, vertigens a circundar o peito, beijos aos círculos, reminiscências de virgem, entrego-me virgem todos os dias, não percebes isto" (A. 1990: 118). A diferença entre ambos os autores consiste no facto de Miller entrar pela esfera do obsceno e de Ruben A., com os mesmos materiais (a partir do corpo), enveredar por um imaginário erótico, mais decoroso.
A construção de Silêncio para 4 é devedora dos Leitmotive que o autor emprega com toda a plenitude, de uma forma circular e metronómica, técnica que é hoje um dos instrumentos mais recorrentes na composição dramática. 0 próprio Ruben A. define o seu drama, talvez em homenagem à Filosofia na Alcova de Sade, como uma "conversa de alcova" (p.75), agradável, onde se discute acerca da liberdade, do sexo, da paixão, do amor, do casamento, do desejo de ter filhos, ou ainda da presença "espiritual" que os seus ex- ou ainda cônjuges têm nas suas vidas. É aí que reside a razão do título, o silêncio (ou a torrente dialógica) é produzido para quatro pessoas, isto é, para os dois amantes e para os fantasmas dos seus amantes que (não) se encontram na cama.

Uma das marcas da teatralidade de Silêncio ancora na corporalidade, no movimento cénico dos corpos, agrupada directamente nos diálogos. Esse movimento, sugerido, ajuda o leitor a visualizar a cama, o desenho dos corpos, as possiveis feições do rosto e o comportamento geral das personagens, assim como a sua disposição para o erotismo. Aliás, o autor consegue no rasgo final do seu texto construir um acto sexual somente através da enunciação de palavras que não explicitam, apenas deixam bem claro o balanço e contra-balanço dos corpos. É esse erotismo doce, sensual, subjugador, que se contrapõe à acidez, à frieza do discurso intelectual e altivo, quase paternalista, da personagem Ele. Talvez esteja no enredo amoroso a justificação para Ruben A. ter chamado ao seu texto "romance", se atribuirmos à palavra o seu sentido mais popular, mais vulgar na nossa sociedade, pois romance pode sempre significar, em língua francesa, uma simples história de amor, une romance. Teria ele chamado ao seu texto "romance", não pela forma, mas pela temática?

\section{4.}

Armando Nascimento Rosa afirma que a peça Triálogo seria "já pós-moderna e desconstrucionista, muito antes de Lyotard e de Derrida anunciarem as fórmulas fluidas na montra da cultura."

Situemos antes o texto Triálogo num campo de experimentação próprio das primeiras vanguardas europeias e das do pós-guerra, reservando o termo pós-moderno para a peça Silêncio para 4, por inaugurar entre nós (e sobretudo no nosso teatro) uma das primeiras "peças" de transgénero. A data da sua criação poderia ser neste âmbito mais um argumento: 1973, inserindo-se assim no começo dessa "montra da fluidez" que marcará a cultura contemporânea.

\section{Referências bibliográficas}

A., Ruben (1990), Silêncio para 4 (1.a ed. 1973), Lisboa, Assírio \&t Alvim. _- (1992-1994), O mundo à minha procura I, III, III, Lisboa, Assírio \&t Alvim. -- (2000), Páginas V, Lisboa, Assírio \&t Alvim. -- (2001), Páginas VI, Lisboa, Assirio \&t Alvim.
${ }^{5}$ Henry Miller, Trópico de Câncer, Lisboa, Livros do Brasil, 1976, p. 16

${ }^{6}$ Armando Nascimento Rosa, "Prefácio: As peças de um narrador dramático" in Ruben A., Triálogo, Júlia e Relato 1453 (Ed. Liberto Cruz), Lisboa, Assirio \&t Alvim, 2007, p. 15. 